\title{
Metabolomics in endometriosis: challenges and perspectives for future studies
}

\author{
Camila N Ortiz1 ${ }^{1}$ Annelyn Torres-Reverón ${ }^{2}$ and Caroline B Appleyard1,3 \\ 1Department of Basic Sciences, Ponce Health Sciences University, Ponce Research Institute, Ponce, Puerto Rico, USA \\ 2DHR Health Institute for Research and Development, Edinburg, Texas, USA \\ 3Department of Internal Medicine, Ponce Health Sciences University, Ponce, Puerto Rico, USA \\ Correspondence should be addressed to C B Appleyard: cappleyard@psm.edu
}

\begin{abstract}
Endometriosis is a complex disease characterized by inflammation and the growth of endometrial- like glands and stroma outside the uterine cavity. The pathophysiology of endometriosis is not entirely understood, however, with a prevalence of $\sim 10 \%$ of women in their reproductive years, the disease symptoms significantly affect the quality of life of millions of women globally. Metabolomic studies have previously identified specific metabolites that could be a signature of endometriosis. This approach could potentially be used as a non-invasive tool for early diagnosis and provide a better understanding of endometriosis pathophysiology. This review aims to provide insight as to how endometriosis affects the metabolome by reviewing different studies that have used this approach to design follow-up studies. The search query included the term 'endometriosis' in combination with 'metabolomics', 'lipidomics', or 'sphingolipidomics' published between 2012 and 2020. We included studies in humans and animal models. Most studies reported differences in the metabolome of subjects with endometriosis in comparison to healthy controls and used samples taken from serum, endometrial tissue, follicular fluid, urine, peritoneal fluid, or endometrial fluid. Statistically significant metabolites contributed to group separation between patients and healthy controls. Reported metabolites included amino acids, lipids, organic acids, and other organic compounds. Differences in methods, analytical techniques, and the presence of confounding factors can interfere with results and interpretation of data. Metabolomics seems to be a promising tool for identifying significant metabolites in patients with endometriosis. Nonetheless, more investigation is needed in order to understand the significance of the study results.
\end{abstract}

\section{Lay summary}

Endometriosis is a chronic disease affecting the quality of life in one out of every ten women during their reproductive years, causing pain and infertility. It is characterized by inflammation and growth of tissue like the endometrium (uterus lining) outside the uterine cavity. Studies have searched for a predictor of endometriosis-associated changes by observing small molecules necessary for metabolism on a large scale (metabolomics). Metabolomics could serve to resolve one of the biggest challenges that patients with endometriosis face: a delay in diagnosis. In this review, the authors summarize identified potential biomarkers from various bodily fluids and tissues that are characteristic of metabolic processes observed in endometriosis. Biomarkers include cell growth, cell survival, high energy demand, oxidative stress, and fatty acid levels. A metabolomics approach offers promise as a non-invasive tool to identify significant metabolite changes in patients with endometriosis, potentially leading to earlier diagnoses and new opportunities for back-translational strategies.

Key Words $•$ endometriosis $\quad$ metabolomics $\quad$ human subjects

(c) 2021 The authors Published by Bioscientifica Ltd

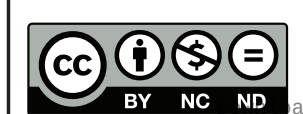

This work is licensed under a Creative Commons Attribution-NonCommercial-NoDerivatives 4.0 International License.
ded from Bioscientifica.com at $04 / 26 / 2023$ 10:47:53AM 


\section{Introduction}

Endometriosis (EMT) is a chronic inflammatory disease characterized by the presence of endometrial-like glands and stroma that can be present within the peritoneal cavity, ovaries, rectovaginal septum, fossa ovarica, uterosacral ligaments, and posterior cul-de-sac (Burney \& Giudice 2012, Mehedintu et al. 2014, Zondervan et al. 2020). The disease affects women during their reproductive ages (Parasar et al. 2017). As reviewed by Parasar et al. (2017), some risk factors include earlier age at menarche, shorter menstrual cycle, taller height, use of alcohol, and caffeine intake. The clinical presentation of endometriosis can vary from woman to woman, but symptoms commonly reported are dysmenorrhea, dyspareunia, dysuria, bleeding in between menstrual cycles, infertility, pelvic pain, painful defecation, and gastrointestinal symptoms (Sinaii et al. 2008, Mehedintu et al. 2014). Although some women are asymptomatic, those who experience these chronic symptoms most often suffer from emotional distress and reduced quality of life, with high levels of stress, anxiety, and depression (Luisi et al. 2015, Appleyard et al. 2020). In fact, it has been demonstrated in an animal model of endometriosis that stress can exacerbate the size and presence of endometriotic lesions (Cuevas et al. 2012, Appleyard et al. 2015). Thus, having the disease may create a cycle of emotional distress that will worsen the symptoms continuously.

The American Society for Reproductive Medicine has classified endometriosis patients within several stages: stage I (minimal), stage II (mild), stage III (moderate) and stage IV (severe). The classification is based on the morphology, number, size, and location of endometriotic lesions (American Society for Reproductive Medicine 1997). Interestingly, there is no association between advanced stages and severity of symptoms (Endometriosis GIplS 2001, Hassa et al. 2005, Sinaii et al. 2008). The confirmatory diagnostic tool is a laparoscopic surgery with histological analysis of a tissue biopsy. This can be complemented by various imaging technologies including ultrasound, MRI and CT (Parasar et al. 2017). Nonetheless, some patients may have atypical or inconsistent symptoms, which delays the diagnosis for approximately 8 to 11 years (Hadfield et al. 1996). In addition, the cause and mechanisms of endometriosis are not well understood. There are several well-accepted theories that could potentially explain the etiology of endometriosis but have not been confirmed (Sampson 1927, Gruenwald 1942, Szyllo et al. 2003, Wu \& Ho 2003).

https://raf.bioscientifica.com

https://doi.org/10.1530/RAF-20-0047 Published by Bioscientifica Ltd
In this context, we have seen that many aspects of endometriosis, such as understanding the pathophysiology, delayed and invasive diagnosis, inconsistent clinical presentation, and unknown etiology, present a challenge for the scientific and medical community which consequently affects patients' health. Several studies have acknowledged these unresolved issues by using a metabolomics-based approach to provide a better understanding of the pathophysiology and potentially mine this information for early diagnosis of endometriosis (Dutta et al. 2012, Ghazi et al. 2016, Dutta et al. 2018, Li et al. 2018a,b).

Metabolomics is the study of small molecules within biofluids or tissues and gives information about the physiological state of a cell tissue or biofluid (EVAR Workgroup et al. 2011, Goulidelmos et al. 2020). Different types of samples, such as tissues, urine, blood, saliva, bronchial washes, CSF, pancreatic juice, and other biofluids, can be utilized (Spratlin et al. 2009). Most of the studies reviewed here used serum, while others used endometrial (ectopic or eutopic) tissue, follicular fluid, urine, peritoneal fluid, or endometrial fluid. The type of sample and the aim of the experiment will determine the choice of instrumentation for data analysis. The most commonly seen analytical techniques in metabolomic studies are NMR and mass spectrometry (MS). NMR requires minimal or no sample preparation without additional fractionation techniques and offers identification of compounds with identical masses and those difficult to ionize (reviewed by Markley et al. 2017). On the other hand, MS requires tissue preparation and is coupled with additional separation techniques such as liquid chromatography (LC) or gas chromatography (GC) but provides more sensitivity in comparison to NMR (reviewed by Klupczyńska et al. 2015). Despite the differences between NMR and MS, both techniques are ideal for data acquisition and it has been suggested that their combined use may provide a more complete picture of the metabolome (reviewed by Bingol \& Brüschwei 2015).

A metabolomic study generates a large amount of data, and once analyzed, the data is subjected to pre-processing and pre-treatment steps involving deconvolution, alignment, scaling, and normalization (Goodacre et al. 2007). This allows the results to be reliable and manageable. Investigators commonly employ multivariate analysis methods such as principal component analysis (PCA) and partial least squares (PLS) to assess metabolomic differences between groups (Putri et al. 2013). Moreover, 
the data is further analyzed by additional statistical analysis, and metabolites can be identified by the use of online databases such as the Human Metabolome Database (HMDB) (Wishart et al. 2007, 2009). Once biomarkers are identified, metabolic pathway analysis can be applied to gain biological understanding and relate the potential role of specific metabolites to disease pathophysiology (Klupczyńska et al. 2015).

This technique has gained interest in the potential identification of key metabolites within mechanistic pathways that play a significant role in the pathophysiology of endometriosis (reviewed by Yang et al. 2017). It has also been considered as a potential diagnostic tool because of its usefulness to monitor disease progression and to distinguish between diseased and healthy subjects using a minimally invasive approach (Nicholson \& Lindon 2008). This review article aims to provide insight about how endometriosis affects the metabolome by reviewing studies that have used this novel approach. We present potential biomarkers of endometriosis that have been found in several studies, discuss the limitations of metabolomic studies, and provide perspectives for back-translational strategies that could be used in animal models of endometriosis.

\section{Methods}

\section{Information sources and search strategy}

To search for articles, we used the electronic database PubMed and Google Scholar. The search query included the following keywords: (1) 'endometriosis' AND 'metabolomics', (2)'endometriosis'AND'sphingolipidomics' and (3) 'endometriosis' AND 'lipidomics'.

\section{Selection process and data collection}

Inclusion criteria: articles must have been published from January 1, 2012 to May 31, 2020, inclusive. The studies were selected based on the research question: 'What is the impact of endometriosis on the metabolome?'. Therefore, articles must have used metabolomics and spectroscopy techniques to identify changes in the metabolome and determine significant metabolites in patients or animal models with endometriosis compared to controls.

Exclusion criteria: articles were excluded if they were published in a language other than English, were purely methodological articles with no results or did not explicitly identify the metabolites. Review articles were also excluded.

Data collection: the first reviewer (CNO) identified the manuscripts in the databases and screened them, applying the inclusion and exclusion criteria systematically. Once the manuscript passed screening, the variables of interest were collected in a tabular format.

\section{Quality assessment}

The second reviewer (ATR) used the Newcastle-Ottawa Assessment Scale (Wells et al. 2013) for measuring the quality of cohort or case-control studies selected by the first author. This scale assigns a maximum of five stars in three different categories (Supplementary Table 1, see section on supplementary materials given at the end of this article). Since animal studies were also included, the Animal Research: Reporting of In Vivo Experiments guidelines 2.0 (ARRIVE) were utilized to measure the quality of the included studies (Percie du Sert et al. 2020). ARRIVE is a checklist of ten items for which we assigned a value of one if a specific criterion was met and a zero if it was not. In each case, the instructions provided by each assessment scale were strictly followed and the total number of points for each manuscript were reported in the corresponding table.

\section{Results and discussion}

The selection process of articles is summarized in Fig. 1. The first search generated a total of 39 studies in PubMed, from which 19 were selected to review. The other 20 studies were eliminated because they were review articles, endometrial cancer studies, studies regarding pregnancy outcome and infertility, did not present specific identification of metabolites, or assessed the performance of different highresolution techniques for endometriosis foci differentiation. The second search resulted in one study. The third search generated eight studies from which two studies were selected, three overlapped with the first search, and three were eliminated because they were article reviews, analysis of an alternative treatment for endometriosis, and another assessment of high-resolution techniques. Google Scholar searches overlapped with studies already identified in PubMed. A total of 19 human studies and 3 animal studies were thus included in this review.

\section{General findings of endometriosis-metabolomic studies}

Our main objective was to find articles demonstrating the impact of endometriosis on the metabolome. The articles selected are listed in Table 1 (human studies) and

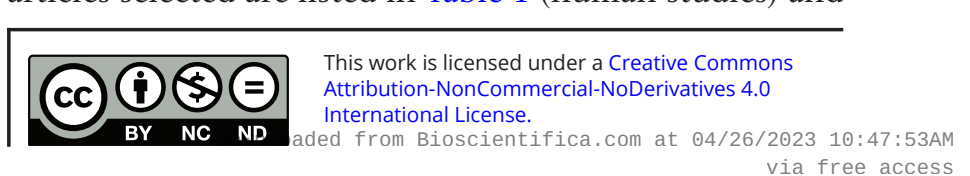




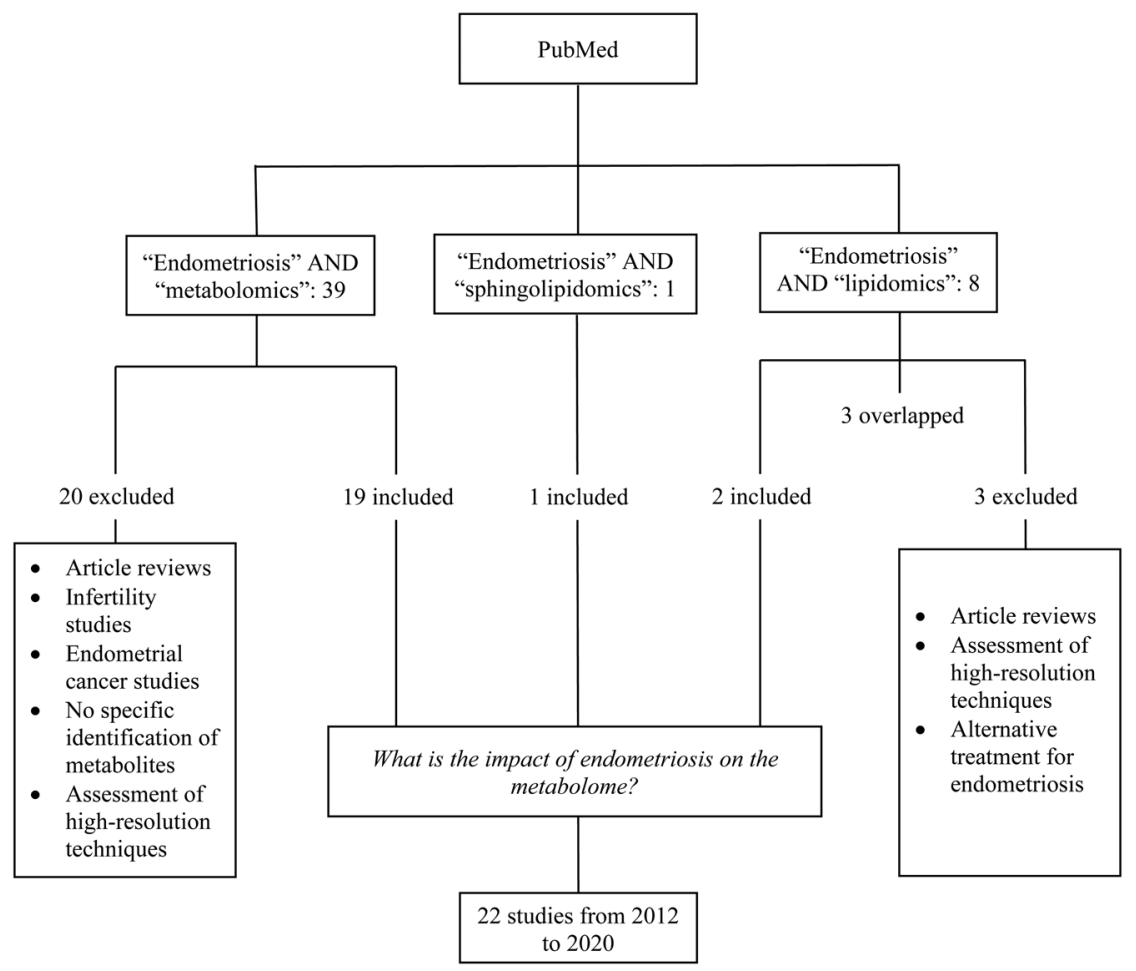

Table 2 (animal models). Overall, the main focus of most studies we reviewed was to determine significant metabolites that distinguish endometriosis patients from healthy controls with the aim of having a better understanding of the pathophysiology. Also, some articles proposed panels of metabolites that could be useful for early detection of the disease. In general, all studies demonstrated group separation between endometriosis subjects and healthy controls. This was seen across all experiments and demonstrates that endometriosis undoubtedly affects the metabolome. However, there are still some challenges and a lack of consensus about what these differences in results could mean, and what could be the most representative panel of metabolites for the different stages of endometriosis. To facilitate the presentation of the findings, we prepared Tables 3, 4, 5 and 6 to visualize statistically significant metabolites identified throughout the manuscripts. We include the nature of the molecule, levels in comparison to healthy controls, sample source, association to stages of endometriosis (if applicable), and references. The following sections of this review discuss how altered levels of amino acids, lipids, organic acids, and other compounds reported in endometriosis samples may be associated with disease pathophysiology. Since the number of animal studies was limited, a summary of their findings and discussion of how these relate to human studies are presented separately.

\section{Amino acids}

Researchers were able to identify altered levels of amino acids in tissue (eutopic endometrium) (Dutta et al. 2018, Li et al. 2018a), serum (Dutta et al. 2012, 2018, Jana et al. 2013, Vicente-Muñoz et al. 2016), follicular fluid (Marianna et al. 2017, Castiglione Morell et al. 2019, Karaer et al. 2019), urine (Vicente-Muñoz et al. 2015) and endometrial fluid (Domínguez et al. 2017) of human subjects with endometriosis. Statistically significant amino acids are listed in Table 3. In comparison to other types of compounds, there seems to be more discrepancy between the levels of amino acids. For example, in two experiments, Dutta et al. $(2012,2018)$ reported increased serum levels of leucine in patients with EMT, while Jana et al. (2013) demonstrated decreased levels. We noted that Dutta et al. collected the samples in women during their mid-secretory and secretory phases (part of the luteal phase) whereas Jana et al. collected samples during the follicular phase. The metabolome is a dynamic system and is susceptible to environmental and genetic changes (Johnson \& Gonzalez 2012); thus, hormonal variations throughout the menstrual cycle phases could have implications on the levels of amino acids. For instance, one of the studies that used urine samples from patients with EMT determined metabolite differences between the follicular phase and luteal phase, but also demonstrated that regardless of the menstrual cycle phase, three metabolites (taurine, unknown metabolite U2, and lysine)

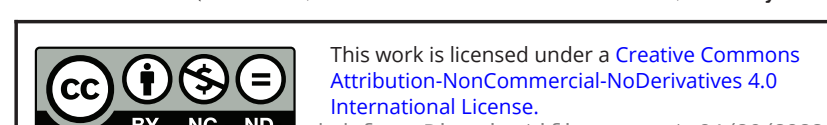
Attribution-NonCommercial-NoDerivatives 4.0 International License. 


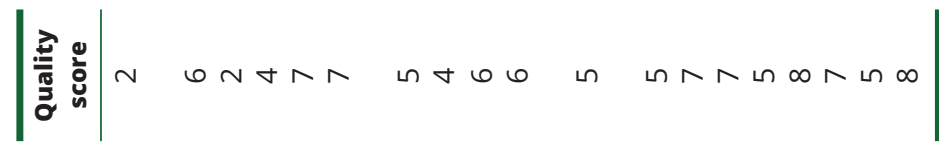

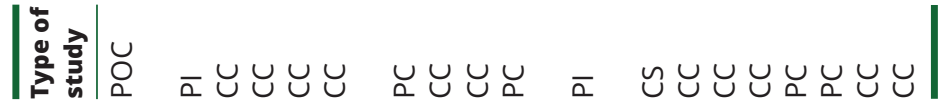

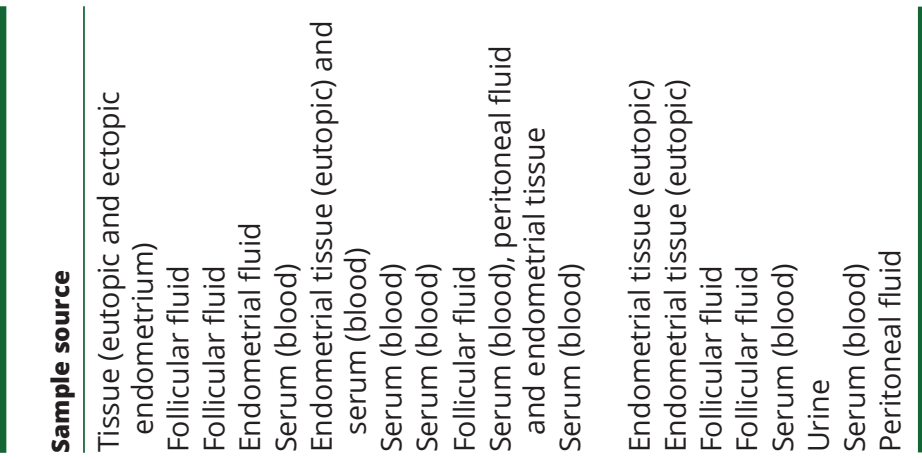
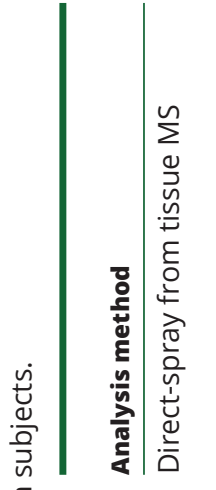

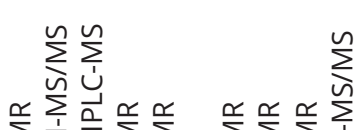

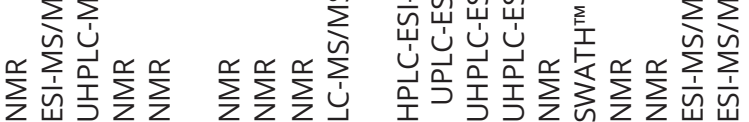

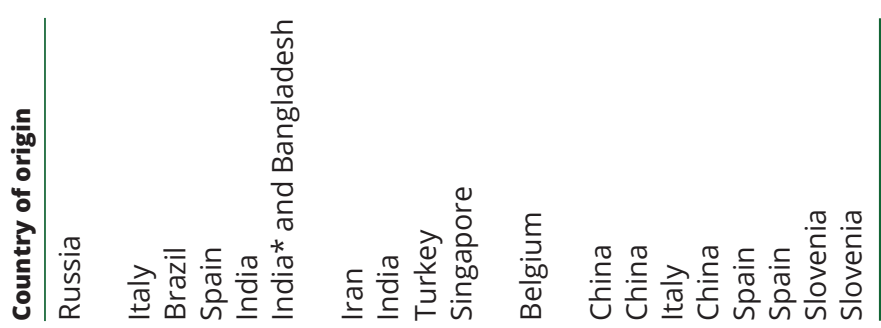

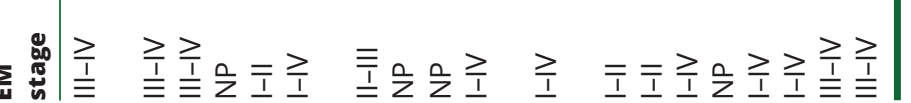

ㅇํำ 워 ํํำ m

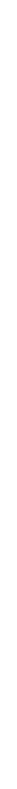

\section{(n)}


Table 2 Characteristics of endometriosis metabolomic studies with animal models.

\begin{tabular}{|c|c|c|c|c|}
\hline Reference & Animal model & Country & Main findings & $\begin{array}{c}\text { Quality } \\
\text { score }\end{array}$ \\
\hline $\begin{array}{l}\text { Atkins et al. } \\
\text { (2019) }\end{array}$ & $\begin{array}{l}\text { Non-human primate } \\
\text { (NHP) model: } \\
\text { Spontaneous } \\
\text { endometriosis in } \\
\text { Macaca fascicularis } \\
\text { and M. mulatta }\end{array}$ & USA & $\begin{array}{l}\text { Endometriotic lesions and endometrium from NHPs with endometriosis } \\
\text { showed decreased mitochondrial respiration in comparison to } \\
\text { healthy controls. } \\
\text { Significant metabolites identified in endometriosis lesions and } \\
\text { endometrium from NHPs with endometriosis include decreased } \\
\text { carnitine, creatine phosphate, NADH, malic acid, FAD and tryptophan. } \\
\text { Pathway analysis of significant metabolites were mapped to tryptophan } \\
\text { and nitrogen metabolism. }\end{array}$ & 8 \\
\hline $\begin{array}{c}\text { Dutta et al. } \\
\text { (2016) }\end{array}$ & $\begin{array}{l}\text { Mouse model: } \\
\text { homologous } \\
\text { C57BL/6] using } \\
\text { syngeneic donor }\end{array}$ & India & $\begin{array}{l}\text { Endometriosis samples evidenced dysregulation of lipids such as } \\
\text { phosphatidylcholines, sphingomyelins, phosphatidylethanolamines } \\
\text { and triglycerides. } \\
\text { Mice with induced endometriosis also demonstrated altered ratio of } \\
\text { phosphatidylcholine/phosphatidylethanolamine. }\end{array}$ & 5 \\
\hline $\begin{array}{l}\text { Ni et al. } \\
(2020)\end{array}$ & $\begin{array}{l}\text { Mouse model: } \\
\text { homologous } \\
\text { C57BL/6J using } \\
\text { syngeneic donor }\end{array}$ & China & $\begin{array}{l}\text { Endometriosis group demonstrated decreased diversity and richness of } \\
\text { bacteria in comparison to the control. } \\
\text { Significant metabolites that contributed to differences in the fecal } \\
\text { metabolome between groups include ALA, CDCA, UDCA and } \\
\text { 12,13-EOTrE. }\end{array}$ & 6 \\
\hline
\end{tabular}

were significantly altered (Vicente-Muñoz et al. 2015). In addition, it has been recognized that one of the significant challenges in metabolomics is the non-standardization of methods and analysis of results (Johnson \& Gonzalez 2012, reviewed by Klupczyńska et al. 2015), which could account for the variety of products found in the experiments overall.

Nonetheless, there is substantial evidence that demonstrates statistically significant differences between EMT and healthy controls. These findings are essential to explain some aspects of disease progression. The altered levels of amino acids potentially explain tissue injury repair mechanisms in endometriosis (Leyendecker et al. 2009) and increased energy demand of proliferative endometrial cells (Bahtiyar et al. 1998). Dutta et al. (2018) state that the catabolic state induced in response to injury in endometriosis leads to increased breakdown of endogenous protein and release of free amino acids in circulation.at' This statement is in agreement with their study, where they found an inverse relationship of amino acid levels between tissue and serum (Table 3) (Dutta et al. 2018). The many similarities of endometrial cells to neoplastic cells, such as high proliferation, angiogenesis, anti-apoptosis, and cell invasion have been extensively recognized in the literature (Varma et al. 2004, Anglesio et al. 2017). All of these characteristics require a high catabolic state from which amino acids could be serving as an important supply since they can be interconverted to the TCA cycle intermediates and support energy requirements for fast-growing endometrial cells (Jana et al. 2013, Li et al. 2018a). In addition, several authors conducted pathway analysis on their data, and their results suggest an imbalance in the metabolism of several amino acids (Dutta et al. 2012, Jana et al. 2013, Marianna et al. 2017).

\section{Lipids}

Characteristic lipid profiles have been identified in tissue (Adamyan et al. 2018, Li et al. 2018b), serum (Vouk 2012), follicular fluid (Cordeiro et al. 2015, Marianna et al. 2017, Sun et al. 2018), peritoneal fluid (Vouk et al. 2016) and endometrial fluid of human subjects with EMT. Statistically significant lipids are illustrated in Table 4. Li et al. (2018b) identified increased levels of lysophosphatidylethanolamine (LysoPE), omega-3 arachidonic acid, and phosphatidic acid (PA), whereas decreased levels of phosphatidylcholine (PC) and phosphatidylserine (PS) were observed in eutopic endometrium. The function of some of these lipids is in parallel with some known aspects of endometriosis pathophysiology. For example, PA is a phospholipid known for its diverse involvement in cellular processes such as 'cell proliferation, cell survival, cell transformation, tumor progression, and differentiation' (Wang et al. 2006, O'Neil et al. 2009). As mentioned earlier, these functions are seen in cancer cells as well as endometrial cells. We could infer that PA may be a chief mediator for cell transformation, survival, and proliferation of endometriotic cells outside the uterine cavity. In addition, PA stimulates oxidative burst leading to the production of reactive oxygen species (ROS) (Wang et al. 2006). This correlates with Jana et al. (2013) and others where they reported lower expression 


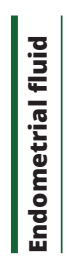

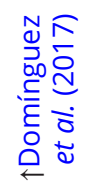$$
\text { |气 }
$$

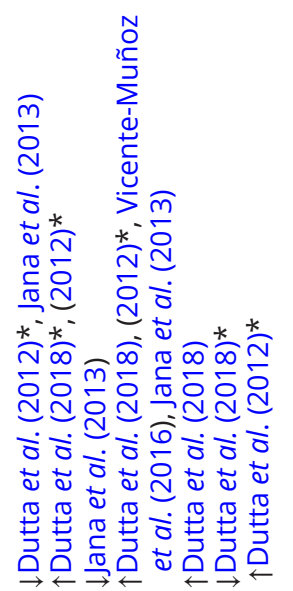

of antioxidative enzymes such as superoxide dismutase (SOD) and catalase and thus, higher production of ROS in the serum of women with EMT (Murphy et al. 1998, Shanti et al. 1999).

Some authors reported altered levels of phosphocholine and phosphatidylcholine in tissue (Adamyan et al. 2018, Li et al. 2018b), follicular fluid (Cordeiro et al. 2015, Marianna et al. 2017), and peritoneal fluid (Vouk et al. 2016). These terms are used interchangeably, but in reality, phosphocholine is an intermediate during the synthesis of phosphatidylcholine, the most abundant phospholipid in mammalian cells. PC has been recognized as a biomarker of cell proliferation in malignant tumors, including breast cancer (Eliyahu et al. 2007). Interestingly, PC is a source for the production of sphingomyelins (SMs) and prostaglandins. SMs have been identified in tissue (Adamyan et al. 2018), follicular fluid (Vouk et al. 2012) and peritoneal fluid (Vouk et al. 2016) and may be involved in the process of denervation and subsequent re-innervation in endometriosis and cell survival (Vouk et al. 2012, Cordeiro et al. 2015). Overall, the functions of most lipids reported by researchers are related to endometrial cell pathophysiology, but as in the case of amino acids, the methodology, statistics, and environmental factors from each experiment should be considered. Nonetheless, lipidomics demonstrates excellent potential for the explanation of mechanistic pathways involved in endometriosis.

\section{Organic acids}

Organic acids are illustrated in Table 5. Statistically significant changes between controls and women with EMT were identified in tissue (Dutta et al. 2018, Li et al. 2018a), serum (Dutta et al. 2012, Jana et al. 2013), follicular fluid (Marianna et al. 2017, Castiglione Morell et al. 2019, Karaer et al. 2019) and urine (Vicente-Muñoz et al. 2015). We have already discussed how endometriosis resembles cancer cells and how altered levels of amino acids could explain the high energy demand of endometrial cells. In this context, several authors have reported increased levels of organic acids supporting the idea of increased energy metabolism in endometriosis (Dutta et al. 2012, Jana et al. 2013, Marianna et al. 2017, Karaer et al. 2019). Organic acids such as pyruvate, succinate, and citrate are important intermediates of the TCA cycle, and some have been reported to be elevated in serum (Dutta et al. 2012, Jana et al. 2013) and follicular fluid (Castiglione Morell et al. 2019, Karaer et al. 2019). This could indicate an upregulation of the TCA cycle for the generation of ATP to supply the rapid proliferation of endometrial cells (Jana et al. 2013). On the 
Table 4 Summary of lipids identified as potential biomarkers from human subjects with endometriosis.

Lipids
Choline
Ceramides
Lysophosphatidylethanolanime
Lysophosphocholine
Omega-3 arachidonic acid
Phosphatidic acid
Phosphatidylcholines
Phosphocholine
Phytosphingosine
Plasmanylcholine, plasmenycholines
Phosphatidylethanolamine
Phosphatidylserine
Sphingomyelins
Sphingolipids
Glucosylceramide
Unsaturated lipids

\begin{tabular}{l}
\hline Tissue $^{\dagger}$ \\
\hline \\
$\uparrow$ Li et al. $(2018 a)^{*}$ \\
$\uparrow$ Li et al. $(2018 a)^{*}$ \\
$\uparrow$ Li et al. $(2018 b)^{*}$ \\
$\downarrow$ Li et al. $(2018 b)^{*}$ \\
$\uparrow$ Adamyan \\
et al. $(2018)^{\ddagger}$
\end{tabular}

et al. (2018)

$\uparrow$ Adamyan et al. (2018) ILi et al. $(2018 b)^{*}$ $\uparrow$ Adamyan et al. $(2018)^{\ddagger}$ Serum

Follicular fluid
\Marianna et al.
$(2017)^{\star \#}$

Peritoneal fluid

(2017)*\#

\Domínguez et al. (2017)

个Sun et al. (2018)

$\uparrow$ Cordeiro et al. $\quad \downarrow$ Vouk et al. (2015)\# (2016)

$\downarrow$ Marianna

et al. (2017)*\#

$\uparrow$ Vouk et al.

$\downarrow$ Sun et al. (2018)

(2012)

个Vouk et al.

(2012)

$\uparrow$ Cordeiro et al. $\begin{array}{ll}\downarrow \text { Vouk et al. } & \downarrow \text { Domínguez } \\ (2016) & \text { et al. (2017) }\end{array}$ (2015)\#

$\uparrow$ Lee et al. (2014) ${ }^{\#}$ $\uparrow$ Lee et al. (2014)\#

$\uparrow$ Castiglione et al.
(2019)

†Ectopic or eutopic endometrium; *I-II (mild-minimal) stages of EMT; \#III-IV (advanced) stages of EMT; ₹Particularly elevated in endometriotic lesions (ectopic) compared to healthy endometrium (eutopic) in patients with endometriosis; $\uparrow$, significantly increased in comparison to controls; $\downarrow$, significantly decreased in comparison to controls.

other hand, researchers have found lower levels of glucose (Dutta et al. 2012, Jana et al. 2013, Marianna et al. 2017) and higher levels of lactate (Dutta et al. 2012, Jana et al.
2013, Marianna et al. 2017, Castiglione Morell et al. 2019, Karaer et al. 2019) in subjects with EMT which indicates high anaerobic metabolism, a phenomenon known as

Table 5 Summary of organic acids identified as potential biomarkers from human subjects with endometriosis.

\begin{tabular}{l}
\hline Organic acids \\
\hline 2-hydroxybutyrate \\
2-hydroxyisovalerate \\
3-hydroxybutyrate \\
$\beta$-hydroxybutyrate \\
Acetate \\
Adipic acid \\
Citric acid \\
Formate \\
Lactate \\
Pyruvate \\
Succinate \\
Taurine \\
Uric acid
\end{tabular}

\begin{tabular}{l}
\hline Tissue $^{\dagger}$ \\
\hline Dutta et al. $(2018)^{\#}$ \\
$\uparrow$ Dutta et al. $(2018)^{\#}$ \\
$\downarrow$ Li et al. $(2018 a)^{*}$
\end{tabular}

Serum
$\begin{gathered}\uparrow \text { Dutta et al. }(2012)^{*} \\ \text { Jana et al. }(2013)\end{gathered}$
Dutta et al. (2012)*

个Jana et al. (2013)

个Jana et al. (2013)

$\uparrow$ Dutta et al. (2012)*, Jana et al. (2013)

个Jana et al. (2013)

$\uparrow$ Dutta et al. (2012)*,

Jana et al. (2013)

Follicular fluid

\section{Urine}

个Vicente-Muñoz et al. (2015)

$\downarrow$ Castiglione et al. (2019)

$\downarrow$ Castiglione et al. (2019)

$\downarrow$ Castiglione et al. (2019)

$\uparrow$ Karaer et al. (2019), Marianna et al. (2017)*\#, Castiglione et al. (2019)

$\uparrow$ Karaer et al. (2019)

†Ectopic or eutopic endometrium; *I-II (mild-minimal) stages of EMT; \#III-IV (advanced) stages of EMT; $\uparrow$, significantly increased in comparison to controls; $\downarrow$, significantly decreased in comparison to controls.

https://raf.bioscientifica.com

https://doi.org/10.1530/RAF-20-0047 (c) 2021 The authors Published by Bioscientifica Ltd
This work is licensed under a Creative Commons Attribution-NonCommercial-NoDerivatives 4.0 International License. ded from Bioscientifica.com at 04/26/2023 10:47:53AM 
the 'Warburg effect' in cancer cells (Young et al. 2014). Moreover, Jana et al. (2013) suggest that impairments in glucose metabolism and mitochondrial respiration could be a potential source of ROS. As previously said, antioxidative enzymes were downregulated in patients with endometriosis (Jana et al. 2013). Specifically, insufficient levels of reduced glutathione (GSH) lead to opthalmate synthesis from which 2-hydroxybutyrate is a byproduct (Fong et al. 2011, Dutta et al. 2012, Jana et al. 2013). This byproduct was found to be elevated in the serum of patients (Dutta et al. 2012, Jana et al. 2013), which correlates ROS to the process of chronic inflammation and tissue damage in endometriosis.

\section{Other compounds}

Compounds such as hormones, sugars, amino acid derivatives, nucleosides, purine derivatives or cholinecontaining compounds are included in Table 6. These were identified in tissue (Dutta et al. 2018, Li et al. 2018a), serum (Dutta et al. 2012, Jana et al. 2013, Ghazi et al. 2016, Letsiou et al. 2017, Vicente-Muñoz et al. 2016), follicular fluid (Marianna et al. 2017, Karaer et al. 2019), urine (Vicente-Muñoz et al. 2015) and peritoneal fluid (Vouk et al. 2016). A metabolite of interest is taurine, which has been associated to high proliferation and cell density (Jong et al. 2012, Vicente-Muñoz et al. 2015, Dutta et al. 2018). In addition, high concentrations have been found in some tumors (Chan et al. 2009, Srivastava et al. 2010, Taherizadeh et al. 2017), which follows the analogy of EMT with neoplasms (Vicente-Muñoz et al. 2015, Dutta et al. 2018). On the other hand, taurine acts as an antioxidant and has been found to be elevated in sites with high oxidative stress (reviewed by Marcinkiewicz \& Kontny 2014). We have already mentioned that endometriosis is characterized by high concentrations of ROS, thus elevated levels of taurine may be playing a role in reducing high oxidative stress conditions (Jeon et al. 2009, Oliveira et al. 2010). In the same manner, Ghazi et al. (2016) found elevated levels of 2-methoxyestradiol, a compound that has gained interest for the treatment of cancer since it has been demonstrated to inhibit angiogenesis and cell proliferation (reviewed by Pribluda et al. 2000). As in the case of taurine, elevated levels of 2-methoxyestradiol could be serving a protecting role to prevent angiogenesis and proliferation of endometrial cells.

One of the enzymes that participates in purine salvage reactions is purine nucleoside phosphorylase (PNP). It has been demonstrated that PNP is teratogenic or lethal to the embryo when it is pharmacologically inhibited (Witte et al. 1991). Li et al. (2018a) suggest an impairment of PNP due to the presence of high concentrations of guanosine, hypoxanthine, inosine, and xanthosine in combination with low levels of uric acid in eutopic endometrium of patients with EMT. Additionally, Kao et al. (2003) demonstrated low expression of PNP in patients with EMT, leading to the conclusion that purine salvage is impaired in EMT and may cause implantation failure. The latter statement could explain the altered levels of purine metabolites reported by Li et al. 2018a) and may relate to the high prevalence of infertility seen in women with endometriosis. Another compound contributing to differences between EMT and healthy controls is glycerophosphocholine or glycerophosphatidylcholine (GPC) (Dutta et al. 2012, Jana et al. 2013, Vicente-Muñoz et al. 2015, 2016). GPC is the product of phospholipase A1 and A2 (PLA2), an enzyme found to be increased in ectopic endometrium from EMT patients (Sano et al. 1994). Interestingly, secretory PLA2 has been demonstrated as a stimulator of vascular endothelial migration, which suggests its potential role in angiogenesis (Rizzo et al. 2000), a process characteristic of endometriotic implants.

\section{Findings in animal models}

We noticed that studies using animal models of endometriosis and metabolomics are limited. From the search engine, we found only three studies, a macaque nonhuman primate model with spontaneous endometriosis and two homologous mouse models where minced endometrial tissue was injected from syngeneic donor mice (Table 2). The nonhuman primate model (Macaca fascicularis and M. mulatta) by Atkins et al. (2019) demonstrated decreased mitochondrial respiration and tissue metabolism in endometrium and endometriosis tissue in comparison to controls. They suggested two possible explanations: mitochondrial damage by ROS from hemoglobin oxidation, inflammatory cells, and electron transport chain or a shift to anaerobic glycolysis to meet the increased energy demands of endometriosis tissue. The second explanation must be supported by further investigation since an increase in lactic acid was not identified. Additionally, they reported decreased levels of tryptophan and metabolites involved in its biosynthesis. This amino acid has not been identified in other studies we have mentioned but might be important since it is thought that its catabolism may be involved in the immune tolerance of endometriosis implants (Urata et al. 2014).

Atkins et al. (2019) also identified significantly decreased levels of carnitine, which was also reported in peritoneal fluid (Vouk et al. 2016) of women with

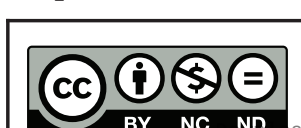

This work is licensed under a Creative Commons Attribution-NonCommercial-NoDerivatives 4.0 International License. International License.
ded from Bioscientifica.com at 04/26/2023 10:47:53AM 

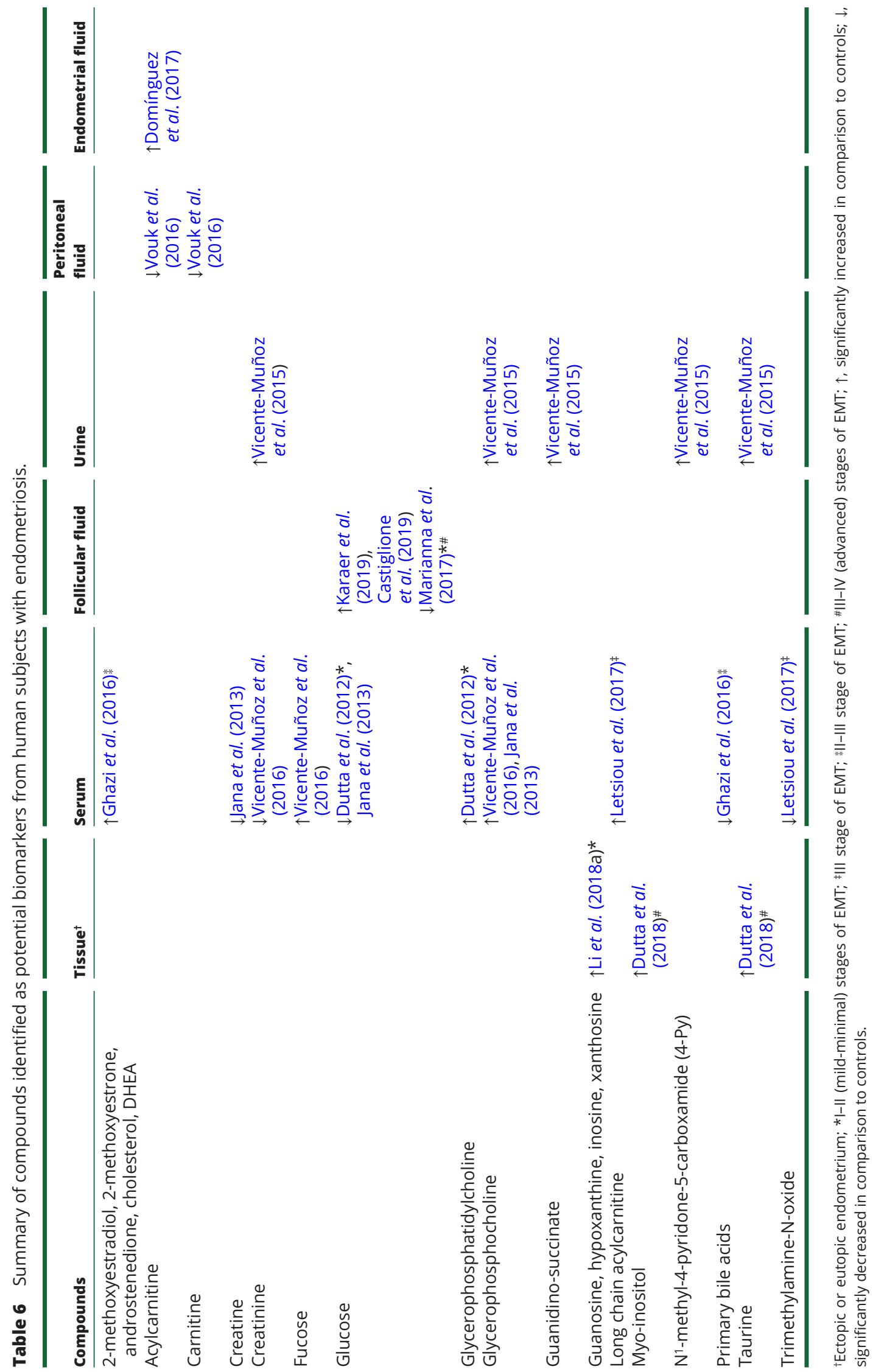
endometriosis (Table 6). L-carnitine (LC) is thought to be beneficial for infertility management (Dunning \& Robker 2012) through its antioxidative effects (Dokmeci 2005). For instance, in a study of patients with polycystic ovarian syndrome (PCOS), LC supplementation improved total antioxidant capacity (TAC), decreased lipid peroxidation, and enhanced general and mental health parameters (Jamilian et al. 2017). Such parameters have been found to be affected in endometriosis patients, suggesting that supplementation of LC could also be beneficial for the treatment of endometriosis. However, as reviewed by Agarwal et al. (2018), the effect of LC on endometriosis is still not well understood since contradictory results have been found. Despite this, altered carnitine levels and its function should be further investigated to understand the relationship between endometriosis, high oxidative stress, and infertility.

The homologous mouse model using female c57BL/6J mice by Dutta et al. (2016) demonstrated dysregulation of lipids such as phosphatidylcholines, sphingomyelins, and phosphatidylethanolamines in the serum of mice with the induced endometriosis. Specifically, sphingomyelin may be involved in cell cycle progression and proliferation since a study with rats demonstrated that inhibition of SM synthesis prevented G1 to S phase transition in uterine epithelial cells (Cerbón et al. 2018). Moreover, sphingolipid metabolism has been reported to be altered in women with endometriosis, and sphingomyelin may be a source of ceramide for the synthesis of glucosylceramide (GlcCer) (Lee et al. 2014). GlcCer has been reported to increase in serum and peritoneal fluid of women with endometriosis and is thought to be an important mediator of enhanced cell proliferation (Lee et al. 2014). As previously mentioned, PC is used as a biomarker for cell proliferation in cancer cells and is a source for sphingomyelin and prostaglandin synthesis.

The other study using the homologous c57BL/6 mouse model is particularly distinctive from the rest of the studies reviewed since it correlates fecal metabolomics and gut microbiota in mice with endometriosis. $\mathrm{Ni}$ et al. (2020) reported decreased diversity and richness of bacteria in an endometriosis group and significant differences in species composition between the disease group and control. In terms of metabolites, alpha-linoleic acid (ALA), chenodeoxycholic (CDCA), ursodeoxycholic acid (UDCA) and 12,13s-epoxy-9z,11,15z-octadecatrienoic acid (12,13-EOTrE) contributed most to differences in fecal metabolome. Ni et al. (2020) suggest that CDCA, UDCA, and ALA have a protective role in the intestinal wall because of their anti-inflammatory effects (Paula et al. 2018, Ko et al. 2019, Song et al. 2019), while 12,13EOTrE may be related to inflammation and serve as a potential biomarker of endometriosis. Despite such findings, further studies are necessary to understand the correlation between endometriosis and these compounds (Ni et al. 2020).

\section{Limitations of the studies}

There is no doubt that endometriosis causes changes in the metabolome, but, as mentioned earlier, metabolomic studies may present challenges in the methodology and interpretation of results and the possibility of bias in metabolite identification. One of the limitations to interpretation as to the clinical significance of any identified metabolites assumes, in part, that all of the studies are comparable in study design. The majority of the studies included in this review were in the upper half of quality scoring for the Newcastle-Ottawa assessment scale suggesting that most studies had comparable criteria for study design and outcomes, regardless, inclusion of some of the studies based on this assumption might contribute to contradictory results. Further, every study uses a different approach for sample extraction, which can influence the type of metabolites identified, adding a source of variability from the beginning. Also, different studies employed various types of spectroscopy (NMR or MS) and other chromatographic techniques, all of which can factor in to influence which specific compounds are ultimately identified. Equally important, investigators used different statistical analytical programs for result interpretation. All of these aspects can affect the outcome of the experiments and thus limit the application of metabolomics to a clinical setting. Most studies propose the use of metabolomics as a tool for early diagnosis of endometriosis; therefore, 'establishment of commonly accepted standardized protocols in the range of methodology, data mining and data reporting is necessary' (Klupczyńska et al. 2015). Nonetheless, metabolomics may be an excellent candidate for the diagnosis of endometriosis since metabolites can be readily measured on semi-invasive samples such as blood and urine. This could resolve one of the major challenges with endometriosis by avoiding the use of laparoscopic surgery for diagnosis.

Another common limitation in the studies we reviewed is the small sample size and the use of invasive samples such as tissue and follicular fluid. The small sample size is to be expected since participants were human subjects and due to exclusion and inclusion 1

Published by Bioscientifica Ltd.

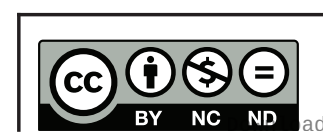

This work is licensed under a Creative Commons Attribution-NonCommercial-NoDerivatives 4.0 International License. 
criteria. The use of tissue involves the use of a biopsy, which is less invasive than laparoscopic surgery but still more invasive than other types of samples employed. Moreover, the acquisition of follicular fluid involves the use of in vitro fertilization (IVF), which also represents an invasive measure. Additionally, IVF treatment requires hormonal supplementation, adding a confounding factor that may interfere with metabolite composition.

Other confounding factors noted throughout the studies included here were differences in menstrual cycle phases, age, BMI, nutrition, medications, diseases, and lifestyle. Earlier, we pointed out the discrepancy between amino acid levels in samples and explained that a factor contributing to these differences might be related to the menstrual cycle phase. For that reason, there should be a consensus regarding in which phase samples should be taken. Another option is to collect samples with a balanced representation of menstrual cycle phases for comparative purposes. Most studies included in their inclusion criteria were age, BMI, and hormonal medication, but some authors did not take these factors into consideration. Lastly, lifestyle was almost never considered in the majority of studies, which also acts as a confounding factor because nutrition, exercise, stress, or environmental factors, in general, could also have an impact on the metabolome. Certainly, lifestyle is difficult or even impossible to control and may represent one of the most challenging confounding factors in human studies.

\section{Further investigation is needed}

We have summarized some of the most important metabolites identified through several metabolomic studies and their association with the pathophysiology of endometriosis. As mentioned earlier, there are factors and limitations that must be considered. However, a metabolomic-based approach seems to be promising since many metabolites relate to some of the cellular processes that have been studied in endometriosis, such as endometrial cell proliferation, cell survival, and high oxidative stress. We found that metabolic studies in animal models or endometriosis are very limited. Nonetheless, the three animal studies we reviewed are in parallel with human studies. Dutta et al. (2016) and Atkins et al. (2019) have demonstrated significant differences between endometriosis and healthy controls and have reported important metabolites implicated in cell proliferation, cell survival, oxidative stress, altered mitochondrial function, high energy demand, and lipid dysregulation. On the other hand, Ni et al. (2020) provided insight into understanding gastrointestinal symptoms commonly experienced by women with endometriosis. The study of the fecal metabolome in subjects with endometriosis is of relevance because it has been documented that women with endometriosis experience more abdominal pain, constipation, the urgency to defecate, bloating, and flatulence in comparison to healthy patients (Ek et al. 2015).

Despite the fact that studies with animals were limited, we suggest that further investigations in animal models of endometriosis could provide valuable information since many confounding factors such as diet, exercise, stress levels, environmental factors, and age can be controlled and standardized. Also, an animal model could allow for increased sampling, which is one of the limitations in research with human studies. Even though rodents do not have a menstrual cycle phase identical to humans, these models exhibit similar signs and symptoms experienced by human subjects, such as reduced fertility and increased vaginal hyperalgesia (reviewed by Grümmer 2006). In addition, as reviewed recently by Appleyard et al. (2020), endometriotic lesions of the rat auto-transplantation model show similar histology, global gene expression profile, and increased cellular and molecular mechanisms to those of human disease, making this an ideal study subject to identify metabolomic changes caused by endometriosis. Therefore, we propose, that in addition to more clinical studies with larger sample sizes and tighter restrictions, future investigations with animal models are also warranted. This approach could eliminate some of the limitations presented in human studies allowing investigation of more samples within the same experiment. For example, from each animal, we can sample various tissues and fluids (e.g. endometrial tissue, peritoneal fluid, endometrial fluid, blood, urine, feces) and investigate the relationship between the levels of metabolites within each sample. Also, we can study the effect of environmental factors such as diet and stressors on the metabolome in animal models of endometriosis. This way, we can investigate how endometriosis and other environmental factors affect the metabolome globally within an individual organism, which can then be extrapolated to human studies and provide insight into the potential use of metabolomics in personalized medicine. https://raf.bioscientifica.com

https://doi.org/10.1530/RAF-20-0047 (c) 2021 The authors Published by Bioscientifica Ltd
This work is licensed under a Creative Commons Attribution-NonCommercial-NoDerivatives 4.0 International License.
aded from Bioscientifica.com at $04 / 26 / 2023$ 10:47:53AM 


\section{Conclusion}

Researchers have recently been using a metabolomicsbased approach to demonstrate differences between endometriosis patients and healthy controls. Statistically significant metabolites such as amino acids, lipids, organic acids, and other biological compounds have contributed to group separation. Metabolomics has caught the interest of researchers as a new tool to understand the pathophysiology of diseases with unknown etiology. However, several limitations and confounding factors persist within the studies. In addition to larger clinical studies with tighter restrictions, we suggest that more animal studies are needed to overcome some of the identified limitations presented here and pinpoint the metabolites with the highest predictive likelihood for diagnosis and prognosis of endometriosis.

Supplementary materials

This is linked to the online version of the paper at https://doi.org/10.1530/ REP-20-0047.

\section{Declaration of interest}

C B A and A T R hold a US patent for repurposing the corticotrophinreleasing hormone inhibitor antalarmin to treat endometriosis. $\mathrm{C} \mathrm{N} \mathrm{O}$ declares no conflict of interest.

\section{Funding}

This report was supported by R15AT009915 from NIH-NCCIH and the Ponce Research Institute.

\section{Author contribution statement}

C B A conceived and supervised the study. C N O collected the data and wrote the first draft of the manuscript. A T R analyzed included papers and edited the final version of this manuscript.

\section{Acknowledgements}

C N O likes to acknowledge her laboratory partners for their support and professional discussions and a special thanks to the Ponce Research Institute for the opportunity to participate in the 2020 MD Summer Research Program.

\section{References}

Adamyan LV, Starodubtseva N, Borisova A, Stepanian AA, Chagovets V, Salimova D, Wang Z, Kononikhin A, Popov I, Bugrova A, et al. 2018 Direct mass spectrometry differentiation of ectopic and eutopic endometrium in patients with endometriosis.
Journal of Minimally Invasive Gynecology 25 426-433. (https://doi. org/10.1016/j.jmig.2017.08.658)

Agarwal A, Sengupta P \& Durairajanayagam D 2018 Role of L-carnitine in female infertility. Reproductive Biology and Endocrinology 16 5. (https://doi.org/10.1186/s12958-018-0323-4)

American Society for Reproductive Medicine 1997 Revised American Society for Reproductive Medicine classification of endometriosis: 1996. Fertility and Sterility 67 817-821. (https://doi.org/10.1016/ s0015-0282(97)81391-x)

Anglesio MS, Papadopoulos N, Ayhan A, Nazeran TM, Noë M, Horlings HM, Lum A, Jones S, Senz J, Seckin T, et al. 2017 Cancer-associated mutations in endometriosis without cancer. New England Journal of Medicine 376 1835-1848. (https://doi.org/10.1056/ NEJMoa1614814)

Appleyard CB, Cruz ML, Hernández S, Thompson KJ, Bayona M \& Flores I 2015 Stress management affects outcomes in the pathophysiology of an endometriosis model. Reproductive Sciences 22 431-441. (https://doi.org/10.1177/1933719114542022)

Appleyard CB, Flores I \& Torres-Reverón A 2020 The link between stress and endometriosis: from animal models to the clinical scenario. Reproductive Sciences 27 1675-1686. (https://doi. org/10.1007/s43032-020-00205-7)

Atkins HM, Bharadwaj MS, O'Brien Cox A, Furdui CM, Appt SE \& Caudell DL 2019 Endometrium and endometriosis tissue mitochondrial energy metabolism in a nonhuman primate model. Reproductive Biology and Endocrinology 17 70. (https://doi.org/10.1186/ s12958-019-0513-8)

Bahtiyar MO, Seli E, Oral E, Senturk LM, Zreik TG \& Arici A 1998 Follicular fluid of women with endometriosis stimulates the proliferation of endometrial stromal cells. Human Reproduction $\mathbf{1 3}$ 3492-3495. (https://doi.org/10.1093/humrep/13.12.3492)

Bingol K \& Brüschweiler R 2015 Two elephants in the room: new hybrid nuclear magnetic resonance and mass spectrometry approaches for metabolomics. Current Opinion in Clinical Nutrition and Metabolic Care 18 471-477. (https://doi.org/10.1097/ MCO.0000000000000206)

Burney RO \& Giudice LC 2012 Pathogenesis and pathophysiology of endometriosis. Fertility and Sterility 98 511-519. (https://doi. $\operatorname{org} / 10.1016 /$ j.fertnstert.2012.06.029)

Castiglione Morell MA, Iuliano A, Schettini SCA, Petruzzi D, Ferri A, Colucci P, Viggiani L, Cuviello F \& Ostuni A 2019 NMR metabolic profiling of follicular fluid for investigating the different causes of female infertility: a pilot study. Metabolomics $\mathbf{1 5}$ 19. (https://doi.org/10.1007/s11306-019-1481-x)

Cerbón J, Baranda-Avila N, Falcón-Muñoz A, Camacho-Arroyo I \& Cerbón M 2018 Sphingolipid synthesis and role in uterine epithelia proliferation. Reproduction 156 173-183. (https://doi. org/10.1530/REP-17-0667)

Chan EC, Koh PK, Mal M, Cheah PY, Eu KW, Backshall A, Cavill R, Nicholson JK \& Keun HC 2009 Metabolic profiling of human colorectal cancer using high-resolution magic angle spinning nuclear magnetic resonance (HR-MAS NMR) spectroscopy and gas chromatography mass spectrometry (GC/MS). Journal of Proteome Research 8 352-361. (https://doi.org/10.1021/pr8006232)

Cordeiro FB, Cataldi TR, Perkel KJ, do Vale Teixeira da Costa L, Rochetti RC, Stevanato J, Eberlin MN, Zylbersztejn DS, Cedenho AP \& Turco EG 2015 Lipidomics analysis of follicular fluid by ESI-MS reveals potential biomarkers for ovarian endometriosis. Journal of Assisted Reproduction and Genetics 32 1817-1825. (https://doi.org/10.1007/s10815-015-0592-1)

Cuevas M, Flores I, Thompson KJ, Ramos-Ortolaza DL, Torres-Reverón A \& Appleyard CB 2012 Stress exacerbates endometriosis manifestations and inflammatory parameters in an animal model. Reproductive Sciences 19 851-862. (https://doi. org/10.1177/1933719112438443) https://raf.bioscientifica.com

https://doi.org/10.1530/RAF-20-0047 (c) 2021 The authors Published by Bioscientifica Ltd
This work is licensed under a Creative Commons Attribution-NonCommercial-NoDerivatives 4.0 International License. ded from Bioscientifica com at 04/26/2023 10:47:53AM 
Dokmeci D 2005 Oxidative stress, male infertility and the role of carnitines. Folia Medica 47 26-30.

Domínguez F, Ferrando M, Díaz-Gimeno P, Quintana F, Fernandez G, Castells I \& Simón C 2017 Lipidomic profiling of endometrial fluid in women with ovarian endometriosis. Biology of Reproduction 96 772-779. (https://doi.org/10.1093/biolre/iox014)

Dunning KR \& Robker RL 2012 Promoting lipid utilization with 1-carnitine to improve oocyte quality. Animal Reproduction Science $\mathbf{1 3 4}$ 69-75. (https://doi.org/10.1016/j.anireprosci.2012.08.013)

Dutta M, Josh M, Srivastava S, Lodh I, Chakravarty B \& Chaudhury K 2012 A metabonomics approach as a means for identification of potential biomarkers for early diagnosis of endometriosis. Molecular bioSystems 8 3281-3287. (https://doi. org/10.1039/c2mb25353d)

Dutta M, Anitha M, Smith PB, Chiaro CR, Maan M, Chaudhury K \& Patterson AD 2016 Metabolomics reveals altered lipid metabolism in a mouse model of endometriosis. Journal of Proteome Research 15 2626-2633. (https://doi.org/10.1021/acs. jproteome.6b00197)

Dutta M, Singh B, Joshi M, Das D, Subramani E, Maan M, Jana SK, Das S, Dasgupta S, Ray CD, et al. 2018 Metabolomics reveals perturbations in endometrium and serum of minimal and mild endometriosis. Scientific Reports 8 6466. (https://doi. org/10.1038/s41598-018-23954-7)

Ek M, Roth B, Ekström P, Valentin L, Bengtsson M \& Ohlsson B 2015 Gastrointestinal symptoms among endometriosis patients: a case-cohort study. BMC Women's Health 15 59. (https://doi. org/10.1186/s12905-015-0213-2)

Eliyahu G, Kreizman T \& Degani H 2007 Phosphocholine as a biomarker of breast cancer: molecular and biochemical studies. International Journal of Cancer 120 1721-1730. (https://doi. org/10.1002/ijc.22293)

Evian Annual Reproduction (EVAR) Workshop Group 2010, Fauser BC Diedrich K, Bouchard P, Domínguez F, Matzuk M, Franks S, Hamamah S, Simón C, Devroey $\mathbf{P}$, et al. 2011Contemporary genetic technologies and female reproduction. Human Reproduction Update 17 829-847. (https://doi.org/10.1093/ humupd/dmr033)

Fong MY, McDunn J \& Kakar SS 2011 Identification of metabolites in the normal ovary and their transformation in primary and metastatic ovarian cancer. PLoS ONE 6 e19963. (https://doi.org/10.1371/journal. pone.0019963)

Ghazi N, Arjmand M, Akbari Z, Mellat AO, Saheb-Kashaf H \& Zamani Z 2016 1H NMR-based metabolomics approaches as non-invasive tools for diagnosis of endometriosis. International Journal of Reproductive BioMedicine 14 1-8. (https://doi.org/10.29252/ ijrm.14.1.1)

Goodacre R, Broadhurst D, Smilde AK, Kristal BS, Baker JD, Beger R, Bessant C, Connor S, Capuani G, Craig A, et al. 2007 Proposed minimum reporting standards for data analysis in metabolomics. Metabolomics 3 231-241. (https://doi.org/10.1007/ s11306-007-0081-3)

Goulielmos GN, Matalliotakis M, Matalliotakis C, Eliopoulos E, Matalliotakis I \& Zervou MI 2020 Endometriosis research in the -omics era. Gene $\mathbf{7 4 1}$ 144545. (https://doi.org/10.1016/j. gene.2020.144545)

Gruenwald P 1942 Origin of endometriosis form the mesenchyme of the celomic walls. American Journal of Obstetrics and Gynecology $4 \mathbf{4}$ 470-474. (https://doi.org/10.1016/S0002-9378(42)90484-8)

Grümmer R 2006 Animal models in endometriosis research. Human Reproduction Update 12 641-649. (https://doi.org/10.1093/humupd/ dml026)

Gruppo Italiano per lo Studio dell'Endometriosi 2001 Relationship between stage, site and morphological characteristics of pelvic endometriosis and pain. Human Reproduction 16 2668-2671. (https:// doi.org/10.1093/humrep/16.12.2668)
Hadfield R, Mardon H, Barlow D \& Kennedy S 1996 Delay in the diagnosis of endometriosis: a survey of women from the USA and the UK. Human Reproduction 11 878-880. (https://doi.org/10.1093/ oxfordjournals.humrep.a019270)

Hassa H, Tanir HM \& Uray M 2005 Symptom distribution among infertile and fertile endometriosis cases with different stages and localizations. European Journal of Obstetrics, Gynecology, and Reproductive Biology 119 82-86. (https://doi.org/10.1016/j. ejogrb.2004.07.025)

Jamilian H, Jamilian M, Samimi M, Afshar Ebrahimi F, Rahimi M, Bahmani F, Aghababayan S, Kouhi M, Shahabbaspour S \& Asemi Z 2017 Oral carnitine supplementation influences mental health parameters and biomarkers of oxidative stress in women with polycystic ovary syndrome: a randomized double-blind, placebo-controlled trial. Gynecological Endocrinology 33 442-447. (https://doi.org/10.1080/095 13590.2017.1290071)

Jana SK, Dutta M, Joshi M, Srivastava S, Chakravarty B \& Chaudhury K 2013 1HNMR based targeted metabolite profiling for understanding the complex relationship connecting oxidative stress with endometriosis. BioMed Research International 2013 1-9. (doi:10.1155/2013/329058], 329058.

Jeon SH, Lee MY, Rahman MM, Kim SJ, Kim GB, Park SY, Hong CU, Kim SZ, Kim JS \& Kang HS 2009 The antioxidant, taurine reduced lipopolysaccharide (LPS)-induced generation of ROS, and activation of MAPKs and Bax in cultured pneumocytes. Pulmonary Pharmacology and Therapeutics 22 562-566. (https://doi. org/10.1016/j.pupt.2009.07.004)

Johnson CH. \& Gonzalez FJ 2012 Challenges and opportunities of metabolomics. Journal of Cellular Physiology 227 2975-2981. (https:// doi.org/10.1002/jcp.24002)

Jong CJ, Azuma J \& Schaffer S 2012 Mechanism underlying the antioxidant activity of taurine: prevention of mitochondrial oxidant production. Amino Acids 42 2223-2232. (https://doi.org/10.1007/ s00726-011-0962-7)

Kao LC, Germeyer A, Tulac S, Lobo S, Yang JP, Taylor RN Osteen K, Lessey BA \& Giudice LC 2003 Expression profiling of endometrium from women with endometriosis reveals candidate genes for disease-based implantation failure and infertility. Endocrinology 144 2870-2881. (https://doi.org/10.1210/en.2003-0043)

Karaer A, Tuncay G, Mumcu A \& Dogan B 2019 Metabolomics analysis of follicular fluid in women with ovarian endometriosis undergoing in vitro fertilization. Systems Biology in Reproductive Medicine 65 39-47. (https://doi.org/10.1080/19396368.2018.1478469)

Klupczyńska A, Dereziński P \& Kokot ZJ 2015 Metabolomics in medical sciences - trends, challenges and perspectives. Acta poloniae pharmaceutica 72 629-641.

Ko WK, Kim SJ, Jo MJ, Choi H, Lee D, Kwon IK, Lee SH, Han IB \& Sohn S 2019 Ursodeoxycholic acid inhibits inflammatory response and promotes functional recovery after spinal cord injury in rats. Molecular Neurobiology 56 267-277. (https://doi.org/10.1007/ s12035-018-0994-z)

Lee YH, Tan CW, Venkatratnam A, Tan CS, Cui L, Loh SF, Griffith L, Tannenbaum SR \& Chan JKY 2014 Dysregulated sphingolipid metabolism in endometriosis. Journal of Clinical Endocrinology and Metabolism 99 E1913-E1921. (https://doi. org/10.1210/jc.2014-1340)

Letsiou S, Peterse DP, Fassbender A, Hendriks MM, van den Broek NJ, Berger R, O DF, Vanhie A, Vodolazkaia A, Van Langendonckt A, et al. 2017 Endometriosis is associated with aberrant metabolite profiles in plasma. Fertility and Sterility $\mathbf{1 0 7}$ 699-706.e6. (https://doi.org/10.1016/j.fertnstert.2016.12.032)

Leyendecker GL, Wildt L \& Mall G 2009 The pathophysiology of endometriosis and adenomyosis: tissue injury and repair. Archives of Gynecology and Obstetrics 280 529-538. (https://doi.org/10.1007/ s00404-009-1191-0)
This work is licensed under a Creative Commons Attribution-NonCommercial-NoDerivatives 4.0 International License. ded from Bioscientifica.com at 04/26/2023 10:47:53AM 
Li J, Guan L, Zhang H, Gao Y, Sun J, Gong X, Li D, Chen P, Liang X, Huang M, et al. 2018a Endometrium metabolomic profiling reveals potential biomarkers for diagnosis of endometriosis at minimal-mild stages. Reproductive Biology and Endocrinology 1642. (https://doi.org/10.1186/s12958-018-0360-z)

Li J, Gao Y, Guan L, Zhang H, Sun J, Gong X, Li D, Chen P, Ma Z, Liang X, et al. $2018 b$ Discovery of phosphatidic acid, phosphatidylcholine and phosphatidylserine as biomarkers for early diagnosis of endometriosis. Frontiers in Physiology 9 14. (https://doi. org/10.3389/fphys.2018.00014)

Luisi S, Pinzauti S, Regini C \& Petraglia F 2015 Serum markers for the non-invasive diagnosis of endometriosis. Women's Health 11 603-610. (https://doi.org/10.2217/whe.15.46)

Marcinkiewicz J \& Kontny E 2014 Taurine and inflammatory diseases. Amino Acids 46 7-20. (https://doi.org/10.1007/s00726-0121361-4)

Marianna S, Alessia P, Susan C, Francesca C, Angela S, Francesca C, Antonella N, Patrizia I, Nicola C \& Emilio C 2017 Metabolomic profiling and biochemical evaluation of the follicular fluid of endometriosis patients. Molecular Biosystems $\mathbf{1 3}$ 1213-1222. (https://doi.org/10.1039/c7mb00181a)

Markley JL, Brüschweiler R, Edison AS, Eghbalnia HR, Powers R, Raftery D \& Wishart DS 2017 The future of NMRbased metabolomics. Current Opinion in Biotechnology 43 34-40. (https://doi.org/10.1016/j.copbio.2016.08.001)

Mehedintu C, Plotogea MN, Ionescu S \& Antonovici M 2014 Endometriosis still a challenge. Journal of Medicine and Life $\mathbf{7}$ 349-357.

Murphy AA, Palinski W, Rankin S, Morales AJ \& Parthasarathy S 1998 Evidence for oxidatively modified lipidprotein complexes in endometrium and endometriosis. Fertility and Sterility 69 1092-1094. (https://doi.org/10.1016/s00150282(98)00087-9)

Ni Z, Sun S, Bi Y, Ding J, Cheng W, Yu J, Zhou L, Li M \& Yu C 2020 Correlation of fecal metabolomics and gut microbiota in mice with endometriosis. American Journal of Reproductive Immunology $\mathbf{8 4}$ e13307. (https://doi.org/10.1111/aji.13307)

Nicholson JK \& Lindon JC 2008 Systems biology: Metabonomics. Nature 455 1054-1056. (https://doi.org/10.1038/4551054a)

O'Neil TK, Duffy LR, Frey JW \& Hornberger TA 2009 The role of phosphoinositide 3-kinase and phosphatidic acid in the regulation of mammalian target of rapamycin following eccentric contractions. Journal of Physiology $\mathbf{5 8 7} 3691-3701$. (https://doi.org/10.1113/ jphysiol.2009.173609)

Oliveira MWS, Minotto JB, de Oliveira MR, Zanotto-Filho A, Behr GA, Rocha RF, Moreira JC \& Klamt F 2010 Scavenging and antioxidant potential of physiological taurine concentrations against different reactive oxygen/nitrogen species. Pharmacological Reports 62 185-193. (https://doi.org/10.1016/s1734-1140(10)70256-5)

Parasar P, Ozcan P \& Terry KL 2017 Endometriosis: epidemiology, diagnosis and clinical management. Current Obstetrics and Gynecology Reports 6 34-41. (https://doi.org/10.1007/s13669-0170187-1)

Paula SD, Rodway LA, Winter T, Taylor CG, Zahradka P \& Aukema HM 2018 Anti-inflammatory effects of $\alpha$-linoleic acid in M1-like macrophages are associated with enhanced production of oxylipins from $\alpha$-linoleic acid and linoleic acid. Journal of Nutritional Biochemistry 57 121-129. (https://doi.org/10.1016/j. jnutbio.2018.03.020)

Percie du Sert N, Hurst V, Ahluwalia A, Alam S, Avey MT, Baker M, Browne WJ, Clark A, Cuthill IC, Dirnagl U, et al. 2020 The ARRIVE guidelines 2.0: updated guidelines for reporting animal research. PLoS Biology 18 e3000410. (https://doi.org/10.1371/ journal.pbio.3000410)

Pribluda VS, Gubish ER, Lavallee TM, Treston A, Swartz GM \& Green SJ 2000 2-Methoxyestradiol: an endogenous antiangiogenic and antiproliferative drug candidate. Cancer Metastasis Reviews 19 173-179. (https://doi.org/10.1023/a:1026543018478)

Putri SP, Yamamoto S, Tsugawa H \& Fukusaki E 2013 Current metabolomics: technological advances. Journal of Bioscience and Bioengineering 116 9-16. (https://doi.org/10.1016/j. jbiosc.2013.01.004)

Rizzo MT, Nguyen E, Aldo-Benson M \& Lambeau G 2000 Secreted phospho-lipase A2 induces vascular endothelial cell migration. Blood 96 3809-3815.

Sampson JA 1927 Peritoneal endometriosis due to the menstrual dissemination of endometrial tissue into the peritoneal cavity. American Journal of Obstetrics and Gynecology 14 422-469. (https://doi. org/10.1016/S0002-9378(15)30003-X)

Sano M, Morishita T, Nozaki M, Yokoyama M, Watanabe Y \& Nakano H 1994 Elevation of the phospholipase A2 activity in peritoneal fluid cells from women with endometriosis. Fertility and Sterility 61 657-662. (https://doi.org/10.1016/s0015-0282(16)56642-4)

Shanti A, Santanam N, Morales AJ, Parthasarathy S \& Murphy AA 1999 Autoantibodies to markers of oxidative stress are elevated in women with endometriosis. Fertility and Sterility $\mathbf{7 1}$ 1115-1118. (https://doi.org/10.1016/s0015-0282(99)00145-4)

Sinaii N, Plumb K, Cotton L, Lambert A, Kennedy S, Zondervan K \& Stratton P 2008 Differences in characteristics among 1,000 women with endometriosis based on extent of disease. Fertility and Sterility 89 538-545. (https://doi.org/10.1016/j. fertnstert.2007.03.069)

Song M, Ye J, Zhang F, Su H, Yang X, He H, Liu F, Zhu X, Wang L, Gao P, et al. 2019 Chenodeoxycholic acid (CDCA) protects against the lipopolysaccharide-induced impairment of the intestinal epithelial barrier function via the FXR-MLCK pathway. Journal of Agricultural and Food Chemistry 67 8868-8874. (https://doi. org/10.1021/acs.jafc.9b03173)

Spratlin JL, Serkova NJ \& Eckhardt SG 2009 Clinical applications of metabolomics in oncology: a review. Clinical Cancer Research $\mathbf{1 5}$ 431-440. (https://doi.org/10.1158/1078-0432.CCR-08-1059)

Srivastava S, Roy R, Singh S, Kumar P, Dalela D, Sankhwar SN, Goel A \& Sonkar AA 2010 Taurine - a possible fingerprint biomarker in non-muscle invasive bladder cancer: a pilot study by $1 \mathrm{H}$ NMR spectroscopy. Cancer Biomarkers 6 11-20. (https://doi. org/10.3233/CBM-2009-0115)

Sun Z, Song J, Zhang X, Wang A, Guo Y, Yang Y, Wang X, Xu K \& Deng J 2018 Novel SWATH ${ }^{\mathrm{TM}}$ technology for follicular fluid metabolomics in patients with endometriosis. Pharmazie 73 318-323. (https://doi.org/10.1691/ph.2018.7193)

Szyllo K, Tchorzewski H, Banasik M, Glowacka E, Lewkowicz P \& Kamer-Bartosinska A 2003 The involvement of T lymphocytes in the pathogenesis of endometriotic tissues overgrowth in women with endometriosis. Mediators of Inflammation 12 131-138. (https://doi.org/10.1080/096293503100 0134842)

Taherizadeh M, Khoshnia M, Shams S \& Joshaghani HR 2017 Comparison of plasma taurine levels between patients with esophageal cancer and healthy controls. Medical Laboratory Journal $111-4$.

Urata Y, Koga K, Hirota Y, Akiyama I, Izumi G, Takamura M, Nagai M, Harada M, Hirata T, Yoshino o, et al. 2014 IL-1 $\beta$ increases expression of tryptophan 2,3-dioxygenase and stimulates tryptophan catabolism in endometrioma stromal cells. American Journal of Reproductive Immunology 72 496-503. (https://doi. org/10.1111/aji.12282)

Varma R, Rollason T, Gupta JK \& Maher ER 2004 Endometriosis and the neoplastic process. Reproduction 127 293-304. (https://doi. org/10.1530/rep.1.00020)

Vicente-Muñoz S, Morcillo I, Puchades-Carrasco L, Payá V, Pellicer A \& Pineda-Lucena A 2015 Nuclear magnetic resonance metabolomic profiling of urine provides a non-invasive alternative

This work is licensed under a Creative Commons Attribution-NonCommercial-NoDerivatives 4.0 International License. ded from Bioscientifica.com at 04/26/2023 10:47:53AM 
to the identification of biomarkers associated with endometriosis. Fertility and Sterility 104 1202-1209. (https://doi.org/10.1016/j. fertnstert.2015.07.1149)

Vicente-Muñoz S, Morcillo I, Puchades-Carrasco L, Payá V, Pellicer A \& Pineda-Lucena A 2016 Pathophysiologic processes have an impact on the plasma metabolomic signature of endometriosis patients. Fertility and Sterility 106 1733-1741.e1. (https://doi.org/10.1016/j.fertnstert.2016.09.014)

Vouk K, Hevir N, Ribič-Pucelj M, Haarpaintner G, Scherb H, Osredkar J, Moller G, Prehn C, Lanisnik Rižner TL \& Adamski J 2012 Discovery of phosphatidylcholines and sphingomyelins as biomarkers for ovarian endometriosis. Human Reproduction 27 2955-2965. (https://doi.org/10.1093/humrep/ des152)

Vouk K, Ribič-Pucelj M, Adamski J \& Rižner TL 2016 Altered levels of acylcarnitines, phosphatidylcholines, and sphingomyelins in peritoneal fluid from ovarian endometriosis patients. Journal of Steroid Biochemistry and Molecular Biology 159 60-69. (https://doi. org/10.1016/j.jsbmb.2016.02.023)

Wang X, Pattada SP, Zhang W \& Welti R 2006 Signaling functions of phosphatidic acid. Progress in Lipid Research 45 250-278. (https:// doi.org/10.1016/j.plipres.2006.01.005)

Wells G, Shea B, O'Connell D, Peterson J, Welch V, Losos M \& Tugwell P 2013 The Newcastle-Ottawa Scale (NOS) for assessing the quality of nonrandomised studies in meta-analyses. (available at: http://wwwohrica/programs/clinical_epidemiology/oxfordasp)

Wishart DS, Tzur D, Knox C, Eisner R, Guo AC, Young N, Gautam B, Hau DD, Psychogios N, Dong E, et al. 2007 HMDB: the Human Metabolome Database. Nucleic Acids Research $\mathbf{3 5}$ D521-D526. (https://doi.org/10.1093/nar/gk1923)
Wishart DS, Knox C, Guo AC, Eisner R, Young N, Gautam B, Hau DD, Psychogios N, Dong E, Bouatra S, et al. 2009 HMDB: a KnowledgeBase for the human metabolome. Nucleic Acids Research 37 D603-D610. (https://doi.org/10.1093/nar/gkn810)

Witte DP, Wiginton DA, Hutton JJ \& Aronow BJ 1991 Coordinate developmental regulation of purine catabolic enzyme expression in gastrointestinal and postimplantation reproductive tracts. Journal of Cell Biology 115 179-190. (https://doi.org/10.1083/jcb.115.1.179)

Wu MY \& Ho HN 2003 The role of cytokines in endometriosis. American Journal of Reproductive Immunology 49 285-296. (https://doi. org/10.1034/j.1600-0897.2003.01207.x)

Yang H, Lau WB, Lau B, Xuan Y, Zhou S, Zhao L, Luo Z, Lin Q, Ren N, Zhao X, et al. 2017 A mass spectrometric insight into the origins of benign gynecological disorders. Mass Spectrometry Reviews 36 450-470. (https://doi.org/10.1002/mas.21484)

Young VJ, Brown JK, Maybin J, Saunders PT, Duncan WC \& Horne AW 2014 Transforming growth factor- $\beta$ induced Warburglike metabolic reprogramming may underpin the development of peritoneal endometriosis. Journal of Clinical Endocrinology and Metabolism 99 3450-3459. (https://doi.org/10.1210/jc.2014-1026)

Zondervan KT, Becker CM \& Missmer SA 2020 Endometriosis. New England Journal of Medicine 382 1244-1256. (https://doi.org/10.1056/ NEJMra1810764)

Received in final form 24 January 2021

Accepted 1 April 2021

Accepted Manuscript published online 1 April 2021 (c) 2021 The authors Published by Bioscientifica Ltd
This work is licensed under a Creative Commons Attribution-NonCommercial-NoDerivatives 4.0 International License. ded from Bioscientifica.com at $04 / 26 / 2023$ 10:47:53AM 